\title{
CARACTERÍSTICAS DOS RELACIONAMENTOS ESTABELECIDOS EM DIFERENTES CONTEXTOS DE SERVIÇOS SOB A ÓTICA DO CONSUMIDOR
}

CHARACTERISTICS OF RELATIONSHIPS ESTABLISHED UNDER DIFFERENT SERVICES CONTEXTS IN THE CONSUMERS POINT-OF-VIEW

\section{RESUMO}

Programas de relacionamento com clientes vêm sendo cada vez mais desenvolvidos pelas empresas de serviços. Na concepção de tais programas, quase sempre as empresas são quem decide com quem querem se relacionar e qual formato o relacionamento deve assumir. Com base em um levantamento e com a utilização da técnica de escalonamento multidimensional, o presente estudo investiga se os consumidores percebem seus relacionamentos com as empresas da mesma forma, ainda que elas sejam de tipos diferentes de serviços, e como as características dos serviços podem ser relacionadas com as percepções dos atributos dos relacionamentos. Os resultados identificam a forma como alguns serviços podem ser agregados de acordo com as características que os consumidores percebem no relacionamento estabelecido entre a empresa e o consumidor. Diante disso, as empresas de serviços podem procurar agrupar seus consumidores com base não mais apenas em suas características, mas na forma como eles percebem e/ou desejam o relacionamento.

\section{Arcanjo Ferreira de Souza Neto}

Professor do Colegiado de Administração, Universidade Federal do Vale do São Francisco - PE, Brasil arcanjo.souza@univasf.edu.br

\section{Sérgio Carvalho Benício de Mello}

Professor do Centro de Ciências Sociais Aplicadas, Universidade Federal de Pernambuco - PE, Brasil

sergio.benicio@gmail.com

Recebido em 20.03.2007. Aprovado em 29.05.2009

Avaliado pelo sistema double blind review

Editor Científico: Delane Botelho

ABSTRACT Customer relationship programs have been increasingly developed by service providing companies. In the conception of such programs, almost always the companies are the ones to decide with whom they want to relate with, and which characteristics the relationship shall have. Based on a survey and by means of multidimensional scaling, the present study investigates if consumers perceive their relationships with the companies in the same way, even when they provide different kinds of service, and how the services characteristics may be related to the perceptions of relationships attributes. The results identify the way some services may be aggregated according to the characteristics consumers identify in the relationship established between the company and the consumer. Considering that, service companies may try to group their consumers based not only on their characteristics, but also on the way they understand and/or expect the relationship to be.

PALAVRAS-CHAVE Marketing de relacionamento, relacionamento empresa-consumidor, marketing de serviços, escalonamento multidimensional, percepção.

KEYWORDS Relationship marketing, company-consumer relationship, services marketing, multidimensional scaling, perception. 


\section{INTRODUÇÃo}

Para Sheth e Parvatiyar (2002), o marketing de relacionamento caminha para se tornar uma subdisciplina do marketing. Apesar de já ter atraído a atenção de um número considerável de pesquisadores e praticantes de marketing em várias partes do globo, tanto no contexto organizacional quanto no de serviços e produtos para o consumidor, os seus fundamentos conceituais ainda não foram totalmente desenvolvidos (ver, por exemplo, as discussões nos textos de BAGOZZI, 1995; LEHTINEN, 1996; FOURNIER, 1998; SAREN e TZOKAS, 1998; KALE e SHRIVASTAVA, 2001) e, assim como o marketing transacional, ele também vem sendo alvo de críticas.

Dentre essas críticas, alguns autores (ex: BARNES, 1997; O'MALLEY, PATTERSON e EVANS, 1997; WONG e SOHAL, 2002) argumentam que a sua aplicação prática tem se revelado problemática e inconsistente, devido às imprecisões que se fazem presentes na definição e operacionalização de seus conceitos, e que ameaçam o êxito das iniciativas tomadas nessa área, pois em vez de fortalecer os vínculos entre a organização e seus consumidores, tais iniciativas em alguns casos os estão deteriorando (ver FOURNIER, DOBSCHA e MICK, 1998; GRAYSON e AMBLER, 1999). Nesse sentido, observa-se que muitas empresas têm ignorado a necessidade de participação voluntária e ativa do consumidor no processo interativo (O'malley e TYNAN, 2000). Mas antes de se poder falar na existência de um relacionamento, as partes envolvidas devem perceber que estão se relacionando, e suas interações devem possuir um caráter especial (BARNES, 1997, WONG e SOHAL, 2002). Assim, um relacionamento não se estabelece só porque os profissionais de marketing alegam que ele existe (GRÖNROOS, 2000), é preciso que o consumidor tenha consciência da natureza do vínculo.

As abordagens válidas para se estudarem os relacionamentos são inúmeras, pois, como observa Fournier (1998), o fenômeno é multifacetado. Mas como geralmente um relacionamento é algo que tem fim em si mesmo (DWYER, 2000), inclusive em várias situações no contexto de consumo (BAGOZZI, 1995), concentrar-se em suas consequências pode não ser suficiente para compreendê-lo por inteiro, o que para as empresas pode trazer prejuízos, pois conduzir um programa de relacionamento com os clientes sem uma compreensão apropriada dos principais aspectos envolvidos em um relacionamento é correr o risco de "passar o carro na frente dos bois" (SOUZA NETO e outros, 2004). Sabendo-se que diferentes formas de relacionamento podem ser estabelecidas no mesmo ou em diferentes contextos (DAY, 2000; BARNES, 1997, 2002), antes de observar o que um relacionamento pode fazer pela empresa e pelo consumidor, parece ser importante compreender como um relacionamento de consumo se configura em cada situação, ou seja, quais as suas peculiaridades.

O que aqui se pretende enfocar diz respeito então às convergências existentes nas formas como os consumidores se relacionam com as organizações que lhes prestam serviços e, principalmente, nas formas como eles intencionam tais relacionamentos. Assim, procurou-se investigar se os consumidores intencionam conduzir e realmente conduzem seus relacionamentos com as empresas da mesma forma, ainda que elas sejam de tipos diferentes de serviço, e como as características dos serviços podem ser relacionadas com as percepções dos atributos dos relacionamentos. Além disso, também se buscou identificar a forma como alguns serviços podem ser agregados de acordo com as características que os consumidores percebem no relacionamento estabelecido entre a empresa e o consumidor.

\section{REFERENCIAL TEÓRICO}

\section{A importância da percepção no relacionamento}

Vários são os autores (ver HINDE, 1979; HAYS, 1988; FOURNIER, 1994, 1998) que defendem a idéia de que o comportamento de cada participante relacional é em algum grau coordenado e influenciado pelo comportamento do outro. Tal perspectiva encontra reforço no fato da sociedade ser baseada em interações, ou seja, baseada na influência recíproca de pessoas que, na medida em que atuam, levam em consideração as características dos outros (STRYKER e STATHAM, 1985; JOAS, 1999). Portanto, o encontro de serviço (base a partir da qual os relacionamentos se constituem e se desenvolvem) pode ser encarado como uma ocasião na qual os atores estabelecem uma "realidade negociada" através da comunicação de símbolos que são desenvolvidos na própria interação, mas que também a moldam (BLUMER, 1969; MELLO, LEÃO e Souza NETO, 2004).

A percepção que os consumidores e os fornecedores têm da experiência de serviço envolve então um processo dialético entre eles mesmos (seus selfs) e os outros que estão sendo percebidos (cf. MEAD, 1934). Essa percepção do outro pode ser formada a partir dos atributos inerentes deste e da interpretação de cada participante sobre esses atributos (HEIDER, 1958). Vale ressaltar que, durante o encontro de serviço, além de perceber os elementos do 
ambiente que o cerca, o indivíduo pode ver a si mesmo assumindo a perspectiva do outro. Ao fazerem isso, os participantes do encontro de serviço podem criar expectativas sobre o curso de ação uns dos outros e, a partir dessas expectativas, guiar seus comportamentos, ajustando-os conforme o contexto no qual a interação ocorrer.

É necessário destacar que o comportamento dos membros da díade não é uma questão de resposta direta às atividades realizadas por cada um, mas envolve uma resposta às suas intenções, pois a resposta do sujeito a uma ação do outro é baseada no significado que o primeiro atribui a essa ação (MEAD, 1934; BLUMER, 1969) - fato que sempre ocorrerá, dado que toda ação é dotada de sentido (WEBER apud COLLIOT-THÉLÈNE, 1995), ainda que tal sentido possa variar de acordo com a interpretação de cada sujeito (BAZILLI e outros, 1998). Considerando-se também que a observação da realidade não pode ser separada da percepção do observador dessa realidade (BAUMAN, 1998), e que tal percepção não pode ser concebida como uma mera impressão de alguma coisa "do exterior" no sistema do indivíduo (Mead, 1934), se os relacionamentos possuem características similares, similaridades podem também ser encontradas na forma como as díades intencionam o relacionamento.

\section{Características dos relacionamentos}

Embora seja difícil traçar uma definição precisa sobre o que constitui um relacionamento, pode-se ao menos encará-lo como uma série de interações inter-relacionadas entre duas ou mais partes (FOURNIER, 1994; HOLMLUND, 2000). Assim, o estudo dos relacionamentos, no contexto de consumo ou fora dele, requer a análise não apenas das características das partes neles envolvidas, mas também das características das interações que elas concretizam (ANDERSON, 1994; DWYER, 2000).

Entre as diversas pesquisas relacionadas às interações sociais e relacionamentos, a abordagem psicológica desenvolvida por Wish (1976) e Wish, Deutsch e Kaplan (1976) proporcionou uma das primeiras avaliações empíricas acerca das propriedades de alguns relacionamentos estabelecidos no cotidiano: por exemplo, paifilho, e marido-esposa. Tais autores identificaram quatro dimensões caracterizadoras das relações interpessoais: simetria-assimetria de poder - os papéis desempenhados por cada indivíduo podem ser encarados com sendo iguais ou desiguais, dominantes ou submissos; valência a relação pode ser enquadrada em um contínuo que vai de cooperativa e amigável à competitiva e hostil; intensidade - reflete a frequência das interações e o comprometimento das partes para a manutenção da relação; e orientação - as relações podem ocorrer de maneira mais informal e socioemocional ou de maneira mais formal e racional. Desde então, várias propriedades dos relacionamentos (reciprocidade, equidade, etc.) desenvolvidas pela Psicologia Social vêm sendo utilizadas na tentativa de compreender como as pessoas percebem um relacionamento de consumo (ver FOURNIER, 1994; SHEAVES e BARNES, 1996; GUMMESSON, 2002; BARNES, 2002). Contudo, a literatura de Marketing ao longo do tempo concentrou esforços na compreensão do papel de alguns desses construtos no relacionamento, notadamente a confiança e o comprometimento (ver, por exemplo, MORGAN e HUNT, 1994; GOSLING e GONÇALVES, 2002; PERIN e outros, 2004), mas até o presente momento poucos estudos empíricos abordaram vários deles simultaneamente.

Em um desses estudos, na tentativa de caracterização das diferenças das relações diádicas estabelecidas entre empresa-empresa, empresa-cliente e indivíduo-indivíduo, Iacobucci e Ostrom (1996) adaptam pela primeira vez os trabalhos de Wish (1976) e Wish, Deutsch e Kaplan (1976) para o contexto de consumo e discutem o impacto de cada forma de relação diádica na natureza dos relacionamentos vivenciados em seus contextos específicos. Assim, a natureza da relação diádica empresa-cliente foi considerada intermediária em relação à natureza dos relacionamentos empresa-empresa e indivíduo-indivíduo, pois apresentou características pertencentes a ambos. Verificou-se que, de um modo geral, a percepção de que existe um relacionamento próximo entre o cliente e uma grande empresa de produtos de consumo tende a ocorrer de forma reduzida - embora não seja impossível, conforme Sheth e Parvatiyar (1995) e Barnes (2002). Normalmente, tal vínculo é percebido por boa parte dos consumidores como focado no aspecto puramente transacional, enquanto a relação com uma pequena empresa tende a ser caracterizada pela informalidade e uma proximidade maior entre as partes.

Segundo Iacobucci e Ostrom (1996), um aspecto interessante no relacionamento empresa-cliente é justamente a sua similaridade com a relação indivíduo-indivíduo. No contexto de serviços, pode-se perceber que tal característica se torna muito mais saliente, pois o cliente em alguma extensão participa do processo de produção de serviços (GRÖNROOS, 2000). Assim, partindo-se do pressuposto que o encontro de serviços é o contexto dos relacionamentos (Rosenberg, 2002), os funcionários de linha de frente podem ser concebidos como os representantes da empresa nas interações do relacionamento empresa-cliente, ou seja, os clientes desenvolvem relacionamento com a empresa, 
mas quem personifica a imagem desta nas interações são seus funcionários (BITNER, 1995). Identifica-se, portanto, que, no relacionamento entre cliente e empresa de serviço, o aspecto interpessoal pode ser de alguma forma inerente à relação (CZEPIEL, 1990; BERRY, 1995).

A literatura afirma ainda que existem serviços eminentemente relacionais, dada a sua complexidade ou periodicidade (LOVELOCK, 1983; BERRY, 2002), como no caso de uma academia de ginástica, ou condições que favoreceriam o estabelecimento de relacionamentos, como, por exemplo, a situação em que a prestação do serviço é muito importante para o consumidor ou envolve muitas incertezas quanto ao resultado final do desempenho (BERRY, 1995; BITNER, 1995; O’MALLEY e TYNAN, 2000).

Apesar dos esforços presentes nos estudos mencionados, verifica-se que as diferenças e semelhanças existentes entre relacionamentos situados em uma mesma forma de relação diádica ainda não foram estudadas a fundo dentro do escopo do Marketing de Serviços.

\section{PROCEDIMENTOS METODOLÓGICOS}

\section{Delineamento da pesquisa}

Esta pesquisa é um levantamento exploratório do tipo corte transversal. O instrumento utilizado foi um questionário estruturado e não disfarçado em relação aos seus objetivos. A partir de um escalonamento multidimensional, tal instrumento permitiu o agrupamento dos serviços estudados de acordo com algumas similaridades relacionais percebidas pelos entrevistados.

\section{Escalonamento multidimensional}

O escalonamento multidimensional (EMD) é o nome genérico de uma série de técnicas analíticas que identificam padrões ocultos nos julgamentos de similaridades ou preferências entre dois ou mais estímulos (marcas, produtos, por exemplo), representando-os em termos de distâncias geométricas em planos uni, bi, tri ou multidimensionais (CARROLL e GREEN, 1997; STALANS, 2002). Cada estímulo é representado por um ponto, e quanto maior é a correlação identificada entre o julgamento dos estímulos, maior é a proximidade das suas representações gráficas. Segundo Green e Rao (1972, p. 5-8), as abordagens conceituais para a realização do EMD podem ser diferenciadas com base em, pelo menos, três descritores:

a) Tarefa dos respondentes: os respondentes julgam as similaridades entre os estímulos com base em critérios não predeterminados pelo pesquisador (julgamentos diretos) ou realizam seus julgamentos avaliando (com "notas" ou "pesos") construtos previamente determinados pelo pesquisador (medidas derivadas). Considerando-se as restrições de tempo e recursos, e as informações já apreendidas junto à literatura, optou-se pela utilização de medidas derivadas.

b) Ênfase do pesquisador: o pesquisador realiza uma análise agregada, assumindo explícita ou implicitamente certo grau de homogeneidade na percepção dos respondentes, ou desagregada, concentrando-se nas diferenças de percepção existentes entre estes. Hair e outros (2005) argumentam que essa escolha deve ser, acima de tudo, baseada nos objetivos do estudo. Considerandose os objetivos do presente estudo e reconhecendo-se, juntamente com Green e Rao (1972, p.7), que, embora o EMD possa ser utilizado em uma pesquisa com um único respondente, pesquisas que possuam mais de um respondente obrigatoriamente já conduzem a análise a alguma forma de agregação de dados, optou-se pela realização de uma análise agregada.

c) Método de escalonamento: o pesquisador utiliza modelos métricos (assumindo as similaridades mensuradas em uma escala ao menos intervalar) ou não métricos (assumindo apenas que a ordem das similaridades é conhecida). A escala adotada neste estudo respalda a adoção do EMD métrico.

\section{Seleção das linhas de serviço}

Inicialmente, levou-se em consideração se a prestação típica do serviço é inerentemente relacional, e se, preferencialmente, no momento do consumo desse serviço o consumidor tem a possibilidade de interagir pessoalmente com pelo menos um funcionário da empresa. A natureza relacional foi apreendida observando-se a existência ou não de um desejo periódico ou contínuo do consumidor pelo serviço, se ele geralmente pode controlar a seleção do fornecedor e se a mudança de um provedor para outro é algo comum no mercado (cf. LOVELOCK, 1983; BERRY, 1995; 2002). Outro critério utilizado foi a possível familiaridade do respondente com a linha de serviço a ser analisada, evitando-se assim serviços com menores probabilidades de integrarem o cotidiano da população pesquisada. Como resultado da aplicação dos referidos critérios, 12 linhas de serviço foram escolhidas: academia de ginástica; agência de viagens; banco; cartão de crédito; escola de idiomas; farmácia; locação de filmes; restaurante fast-food; supermercado; salão de beleza; transporte aéreo e telefonia móvel. Ressalta-se que essa lista tem, acima de tudo, caráter exemplificativo-operacional e não pretende ser exaustiva, pois outros serviços podem ser enquadrados nos critérios discriminados. 


\section{Seleção da população e tamanho da amostra}

A população arbitrariamente considerada para fins deste estudo é constituída por moradores de uma grande capital nordestina que possuem renda familiar mensal acima de R\$ 2.000,00 (critério adotado visando maximizar o número médio de serviços consumidos), têm entre 20 e 59 anos e já concluíram o ensino médio ou o estão cursando (estes dois últimos critérios adotados em virtude do nível de esforço cognitivo e capacidade abstrativa necessários para o preenchimento do instrumento de coleta).

Como não se teve condições de determinar o número exato de elementos da população acima descrita, adotou-se a amostragem não probabilística por cotas (ver MALHOTRA, 2001). Com base nos dados do IBGE (2001), verificou-se que o percentual de residentes homens na cidade em questão é $45,6 \%$, e que os habitantes apresentam a seguinte distribuição com relação à idade: $34,4 \%$ possuem entre 20 e 29 anos; 29,2\% entre 30 e 39 anos, 22,2\% entre 40 e 49 anos e 14,2\% entre 50 e 59 anos. Considerando-se o tipo de análise que se pretendia realizar e as características do instrumento de coleta, a quantidade de questionários válidos a ser coletada foi estipulada em 300, distribuída pelas referidas proporções de gênero e idade. As variáveis renda e grau de instrução não foram consideradas para fins desta distribuição por três motivos. Primeiro, porque os critérios estabelecidos (R\$ $2.000,00$ e $2^{\circ}$ grau, respectivamente) funcionaram apenas como "pontos de corte" na determinação da população. Segundo, porque não se teve como obter informações precisas em fontes secundárias acerca da distribuição da população nestas variáveis observando exatamente os intervalos desejados. Terceiro, porque ainda que estas informações existissem, elas aumentariam em demasia o número de questionários a serem coletados para que todas as proporções pudessem ser simultaneamente satisfeitas.

\section{Instrumento de coleta de dados}

O instrumento de coleta de dados foi construído com base nos trabalhos de Wish (1976), Wish, Deutsch e Kaplan (1976), Sheaves e Barnes (1996), Iacobucci e Ostrom (1996), Gummesson (2002), Barnes (2002) e Souza Neto e outros (2004). Na primeira parte, para garantir avaliações mais vívidas e fidedignas, solicitou-se aos respondentes que indicassem os serviços que utilizavam ou já tinham utilizado nos últimos seis meses. Na segunda parte, os respondentes, a depender de suas respostas anteriores, poderiam avaliar, por meio de uma escalar intervalar de 7 pontos, até 12 relacionamentos diferentes com base em 24 atributos previamente determinados (construídos com base nas propriedades dos relacionamentos discutidas $e$ operacionalizadas no conjunto de textos supramencionados, em especial o de Iacobucci e Ostrom, 1996) e apresentados em forma de pares de assertivas para facilitar o seu entendimento, conforme pode ser observado no Quadro 1.

Ressalta-se que foi elaborado um alerta para que o respondente avaliasse o relacionamento e não os elementos da díade isoladamente. Versões anteriores do instrumento foram submetidas a três doutores em Marketing para fins de vali-

Quadro 1 - Operacionalização dos atributos utilizados

\begin{tabular}{|l|l|l|l|}
\hline CÓD. & \multicolumn{1}{|c|}{ ATRIBUTO } & \multicolumn{1}{c}{ OPERACIONALIZAÇÃO DO ATRIBUTO } \\
\hline AT1 & Equidade & $\begin{array}{l}\text { Cliente e empresa nunca procuram levar vantagem um sobre o outro - Cliente e empresa } \\
\text { sempre procuram levar vantagem um sobre o outro }\end{array}$ \\
\hline AT2 & $\begin{array}{l}\text { Compatibilidade de desejos e } \\
\text { objetivos }\end{array}$ & $\begin{array}{l}\text { Os objetivos e desejos do cliente e da empresa são totalmente compatíveis - Os obje- } \\
\text { tivos e desejos do cliente e da empresa são totalmente incompatíveis }\end{array}$ \\
\hline AT3 & Hostilidade & $\begin{array}{l}\text { Cliente e empresa interagem de forma amigável - Cliente e empresa interagem de for- } \\
\text { ma hostil }\end{array}$ \\
\hline AT4 & Egoísmo & $\begin{array}{l}\text { Cliente e empresa agem levando em consideração o interesse do outro - Cliente e em- } \\
\text { presa agem levando em consideração apenas seus interesses }\end{array}$ \\
\hline AT5 & Poder & $\begin{array}{l}\text { Cliente e empresa têm capacidades similares para influenciar as ações um do outro - } \\
\text { Uma das partes tem mais capacidade para influenciar as ações da outra }\end{array}$ \\
\hline AT6 & Cooperação & $\begin{array}{l}\text { Cliente e empresa procuram conciliar esforços visando o benefício mútuo - Cliente e } \\
\text { empresa disputam entre si visando a exclusividade de um benefício }\end{array}$ \\
\hline AT7 & Conflito & $\begin{array}{l}\text { Cliente e empresa interagem de forma harmoniosa - Cliente e empresa interagem de } \\
\text { forma conflituosa }\end{array}$ \\
\hline
\end{tabular}


(conclusão)

\begin{tabular}{|c|c|c|}
\hline At8 & Estímulo & $\begin{array}{l}\text { Cliente e empresa vêem a relação como estimulante - Cliente e empresa vêem a rela- } \\
\text { ção como entediante }\end{array}$ \\
\hline At9 & Racionalidade & $\begin{array}{l}\text { Cliente e empresa interagem de forma emocional - Cliente e empresa interagem de } \\
\text { forma racional }\end{array}$ \\
\hline At10 & Frequência de interação & $\begin{array}{l}\text { Cliente e empresa interagem com grande frequência - Cliente e empresa raramente } \\
\text { interagem }\end{array}$ \\
\hline At11 & Intensidade & $\begin{array}{l}\text { Cliente e empresa interagem de forma intensa - Cliente e empresa interagem de forma } \\
\text { superficial }\end{array}$ \\
\hline At12 & Similaridade de papéis & $\begin{array}{l}\text { Cliente e empresa desempenham ações de mesma natureza das ações do outro - Cliente } \\
\text { e empresa desempenham ações de natureza diferente das ações do outro }\end{array}$ \\
\hline At13 & Proximidade & Cliente e empresa sentem-se próximos - Cliente e empresa sentem-se distantes \\
\hline At14 & Produtividade & $\begin{array}{l}\text { Cliente e empresa vêem a relação como produtiva - Cliente e empresa vêem a relação } \\
\text { como destrutiva }\end{array}$ \\
\hline At15 & Facilidade de término & $\begin{array}{l}\text { Cliente e empresa podem romper facilmente os vínculos entre si - Cliente e empresa } \\
\text { encontram grandes dificuldades para romper os vínculos entre si }\end{array}$ \\
\hline At16 & Horizonte de interação & $\begin{array}{l}\text { Cliente e empresa interagem focando prioritariamente o curto prazo - Cliente e empresa } \\
\text { interagem focando prioritariamente o longo prazo }\end{array}$ \\
\hline At17 & Confiança & Cliente e empresa confiam um no outro - Cliente e empresa são céticos um com o outro \\
\hline At18 & Risco & $\begin{array}{l}\text { Cliente e empresa vêem a relação como segura - Cliente e empresa vêem a relação } \\
\text { como arriscada }\end{array}$ \\
\hline At19 & Comprometimento & $\begin{array}{l}\text { Cliente e empresa são muito comprometidos com a relação - Cliente e empresa são } \\
\text { descomprometidos com a relação }\end{array}$ \\
\hline At20 & Reciprocidade & $\begin{array}{l}\text { Cliente e empresa agem de forma a retribuir o que recebem um do outro - Cliente e } \\
\text { empresa não fazem concessões recíprocas }\end{array}$ \\
\hline At21 & Transparência & $\begin{array}{l}\text { Cliente e empresa buscam não esconder nada um do outro } 3 / 4 \text { Cliente e empresa não } \\
\text { são transparentes um com o outro }\end{array}$ \\
\hline At22 & Respeito & $\begin{array}{l}\text { Cliente e empresa interagem de forma respeitosa - Cliente e empresa interagem de } \\
\text { forma desrespeitosa }\end{array}$ \\
\hline At23 & Formalidade & $\begin{array}{l}\text { Cliente e empresa interagem de maneira formal - Cliente e empresa interagem de ma- } \\
\text { neira informal }\end{array}$ \\
\hline At24 & Importância do histórico & $\begin{array}{l}\text { Cliente e empresa valorizam a história do relacionamento para a continuação da rela- } \\
\text { ção - Cliente e empresa menosprezam a história do relacionamento para a continua- } \\
\text { ção da relação }\end{array}$ \\
\hline
\end{tabular}

dação de face, solicitando-se a estes que opinassem sobre a adequação do formato, vocabulário e seqüência das perguntas, bem como sobre o leiaute do instrumento. O questionário também foi pré-testado em uma amostra de 30 pessoas e o resultado do pré-teste serviu para a sua revisão final.

\section{Procedimentos de coleta de dados}

Os respondentes foram contatados em locais de grande circulação pública (universidades, praças, etc.) e apenas aqueles que indicaram ser consumidores (e realizaram a avaliação) de pelo menos metade dos serviços estudados foram considerados válidos. A Tabela 1 apresenta a quantidade de avaliações realizadas para cada serviço, salientando-se que 7,7 foi a quantidade média de serviços analisados por respondente.

Tentando reduzir vieses devido ao cansaço dos respondentes e também ao efeito carry-over (ver NETER, WASSERMAN e KUTNER, 1990), duas versões do questionário foram construídas variando a ordem dos serviços apresentados. 


\section{Procedimentos preparatórios para a análise de dados}

A coleta de dados gerou 300 matrizes individuais de ordem variável (pois a quantidade de serviços avaliados variou segundo o respondente) onde as colunas representavam os relacionamentos e as linhas, os atributos utilizados para avaliá-los. Inicialmente, para a utilização do método de escalonamento clássico de Torgerson, os dados dessas matrizes foram agregados por meio do cálculo da média aritmética para cada uma das células (cf. STALANS, 2002; HAIR e outros, 2005), observando-se a quantidade de avaliações descritas na Tabela 1. Após isso, uma matriz de dados brutos agregados de ordem 24 x 12 foi gerada. Com o auxílio do SPSS 11.0 (algoritmo ALSCAL), essa matriz foi transformada em uma matriz de distância euclidiana quadrática de ordem 12 x 12 que foi utilizada como fonte para a geração das coordenadas dos estímulos no mapa perceptual.

\section{Determinação da dimensionalidade da configuração} Os softwares utilizados para a realização do EMD não selecionam automaticamente a configuração mais apropriada, é o pesquisador que tem que analisar como cada configuração com diferentes dimensionalidades se ajusta aos dados e escolher aquela que propicie o melhor ajuste, a maior estabilidade e a maior facilidade de interpretação (STALANS, 2002). Deve-se buscar um ponto a partir do qual o acréscimo no número de dimensões não compense mais a melhoria relativa dos índices de desajuste (SOUZA e BUSSAB, 2003; HAIR e outros, 2005). Consideram-se aceitáveis valores de R2 a partir de 0,60.
Tanto no índice de Stress quanto no S-stress, valores próximos a 0,05 indicam bom ajuste e a 0,10 indicam ajuste razoável. Contudo, a observação do S-stress é aqui mais relevante devido ao algoritmo ALSCAL utilizado (BORG e GROENEN, 1997). Analisando-se o conjunto de indicadores apresentados na Tabela 2, optou-se por uma configuração bidimensional.

Tal opção foi reforçada pelo Gráfico 1, pois o ponto em que se observa uma inflexão é indicativo do número apropriado de dimensões.

O Gráfico 2 indica que a configuração bidimensional escolhida é uma solução não degenerada, pois a relação entre as distâncias e as disparidades apresenta aspecto linear.

\section{ANÁLISE DOS RESULTADOS}

Antes da análise do mapa perceptual, é interessante comparar os valores das médias das avaliações de cada atributo pesquisado. A Tabela 3 indica que, de modo geral, as "piores" avaliações são atribuídas aos relacionamentos estabelecidos entre consumidores e empresas que atuam respectivamente no segmento de banco, cartão de crédito, telefonia móvel e transporte aéreo. Em comum, a oferta desses serviços tende a ser realizada por grandes organizações, as quais em alguns casos possuem atuação restrita à esfera estadual, mas na maioria das vezes exercem suas atividades no âmbito regional, nacional ou até mesmo internacional. Tais ofertas são também marcadas pela presença direta e cada vez mais relevante da tecnologia, a qual em

Tabela 1 - Quantidade de avaliações realizadas em cada linha de serviço

\begin{tabular}{|c|c|c|}
\hline SERVIÇO & AVALIAÇÕES & $\%$ DO TOTAL (300) \\
\hline Academia de ginástica & 132 & 44 \\
\hline Agência de viagens & 85 & 28 \\
\hline Banco & 278 & 93 \\
\hline Cartão de crédito & 251 & 84 \\
\hline Escola de idiomas & 85 & 28 \\
\hline Farmácia & 255 & 85 \\
\hline Locação de filmes & 199 & 66 \\
\hline Restaurante fast-food & 233 & 78 \\
\hline Supermercado & 256 & 85 \\
\hline Salão de beleza & 199 & 66 \\
\hline Transporte aéreo & 65 & 22 \\
\hline Telefonia móvel & 244 & 81 \\
\hline
\end{tabular}


algumas ocasiões (às vezes sem que seja dada escolha ao consumidor) pode chegar a ofuscar a importância ou até mesmo a necessidade da interação do consumidor com funcionários da empresa. Além disso, constata-se que a aquisição desses serviços por parte do consumidor tem um forte caráter instrumental. Eles tipicamente não são procurados e consumidos com finalidade em si mesmos, mas principalmente como forma de viabilizar algo que, em tese, poderia ser obtido de muitas outras formas, mas que por alguma razão restritiva (momentânea ou perene) se torna de mais fácil obtenção por intermédio do consumo desses serviços.

A observação da Tabela 3 permite ainda a elaboração de um "perfil relacional" percebido para as quatro linhas de serviço com tendências a obtenção das "piores" ava- liações. Assim, as principais tendências identificadas nas percepções dos entrevistados sugerem que as partes envolvidas nessas díades em geral são encaradas como valorizando o histórico de interações para a continuação da relação e, talvez por isso, interagindo com foco no longo prazo. Atrelado a isso, elas (talvez os consumidores um pouco mais), por alguma razão, encontram certo nível de dificuldade para romper os vínculos que estabeleceram entre si (dificuldades que são bem menos percebidas no caso das companhias aéreas), o que pode fazer com alguns desses vínculos possam ser encarados como "relacionamentos forçados". Como os objetivos e desejos de cada uma das partes das díades não são percebidos como totalmente compatíveis, acredita-se que elas (pelos mais variados motivos e nas mais distintas ocasiões) não sejam

Tabela 2 - Indicadores de desajuste do modelo para auxílio na determinação da dimensionalidade da configuração

\begin{tabular}{|c|c|c|c|c|c|c|}
\hline \multirow{2}{*}{$\begin{array}{l}\text { DIMENSIONALIDADE } \\
\text { DA SOLUÇÃO }\end{array}$} & \multicolumn{6}{|c|}{ MEDIDAS DE DESAJUSTE } \\
\hline & STRESS a & $\begin{array}{l}\text { ALTERAÇÃO } \\
\text { PERCENTUAL }\end{array}$ & S-STRESS ${ }^{b}$ & $\begin{array}{l}\text { ALTERAÇÃO } \\
\text { PERCENTUAL }\end{array}$ & R2 & $\begin{array}{l}\text { ALTERAÇÃO } \\
\text { PERCENTUAL }\end{array}$ \\
\hline 4 & 0,06721 & $3 / 4$ & 0,05337 & $3 / 4$ & 0,97928 & $3 / 4$ \\
\hline 3 & 0,08441 & 25,6 & 0,05868 & 9,9 & 0,97135 & 0,8 \\
\hline 2 & 0,10999 & 30,3 & 0,06501 & 10,8 & 0,96026 & 1,2 \\
\hline 1 & 0,15890 & 44,5 & 0,09250 & 42,3 & 0,92661 & 3,6 \\
\hline
\end{tabular}

$a=$ Utilizou-se a fórmula 1 de Kruskal.

$b=$ Utilizou-se a fórmula 1 de Young.

Gráfico 1 - S-stress versus dimensionalidade

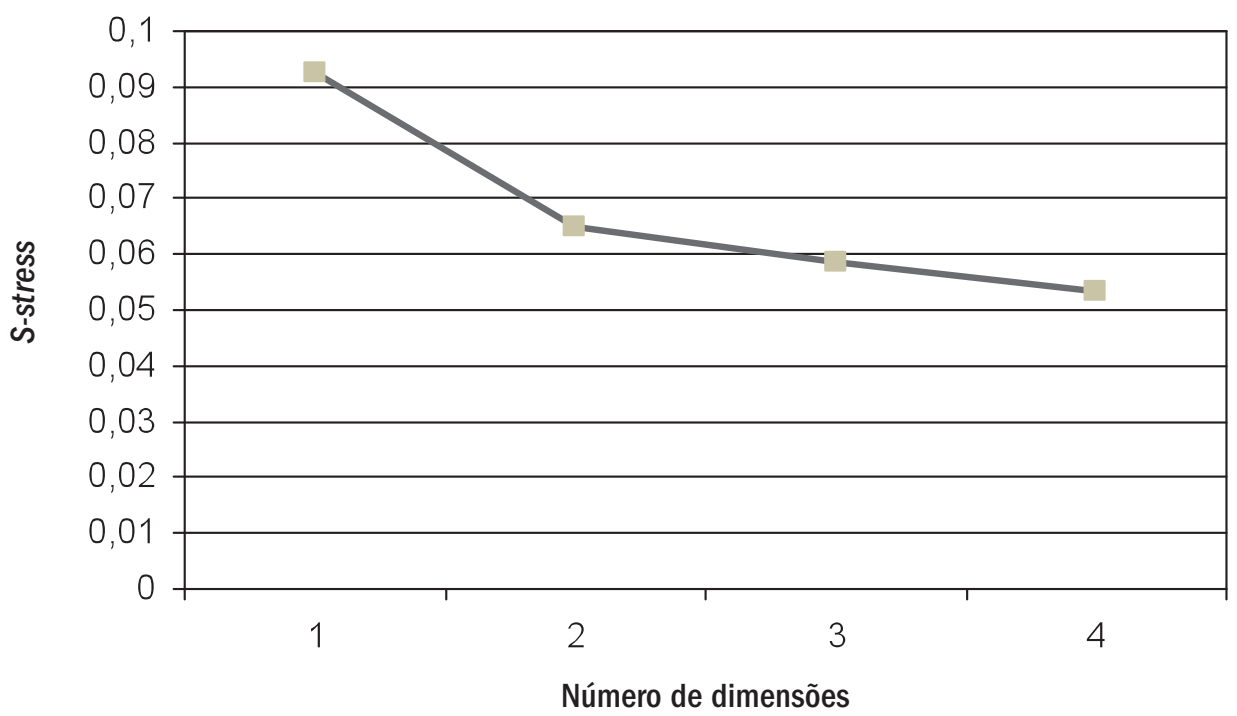


completamente transparentes uma em relação à outra, não possuam, talvez justamente por isso, um nível elevado de confiança mútua, ajam levando em consideração principalmente os seus interesses e não façam muitas concessões recíprocas. É possivelmente em decorrência de tais aspectos que os elementos dessas relações, em vez de serem percebidos como agentes que procuram conciliar esforços em prol do benefício mútuo, tendem a ser vistos em disputa pela exclusividade de um benefício, buscando, sempre que possível, alguma vantagem sobre o outro, embora a um deles (empresa) seja atribuída mais capacidade para influenciar as ações do outro. Verifica-se ainda que essas relações tendem a ser percebidas como entediantes, concretizadas por interações formais e racionais, permeadas por desrespeito e que fazem com que os interagentes se sintam distantes uns dos outros.

Passando-se agora à identificação das relações às quais, de um modo geral, são atribuídas as "melhores" avaliações, verifica-se a formação de um grupo composto pelos relacionamentos estabelecidos entre consumidores e empresas que atuam respectivamente no segmento de academia de ginástica, escola de idiomas, salão de beleza e locação de filmes. Inicialmente, observa-se que a oferta desses serviços tanto pode ser realizada por grandes empresas (as quais, neste caso, geralmente são franquias, como pode ser verificado nas escolas de idiomas e nas locadoras de vídeo) como (aparentemente com maior frequência) por organizações menores e de atuação restrita à esfera local (uma cidade ou até mesmo um bairro). Tais ofertas são marcadas também pelo contato direto, e de certo modo mais acentuado, do consumidor com algum funcionário da empresa (até mesmo no caso da locação de filmes, quando o consumidor, por exemplo, recebe dicas sinalizadoras das opções mais adequadas) e pela possibilidade de estabelecimento de "relacionamentos laterais" entre consumidores que estão em interação simultânea (ou quase) com o mesmo prestador do serviço. Em algumas situações, esses vínculos podem servir de base à criação de comunidades ou "tribos", cujos membros, unidos inicialmente por conta de algum interesse ou preferência em comum, mantêm contato mesmo fora do ambiente de consumo do serviço. Existe, portanto, a possibilidade de que alguns consumidores atribuam tanto (ou até mais) valor aos relacionamentos que estabelecem entre si quanto ao próprio serviço que estão consumindo. Verifica-se ainda que o consumo de cada um desses serviços requer um considerável nível de envolvimento do corpo e/ou da mente de quem os consome e, por isso, o sucesso do resultado final do serviço está bastante atrelado à eficácia do papel desempenhado pelo próprio consumidor.

A Tabela 3 permite também a elaboração de um "perfil relacional" percebido para as quatro linhas de serviço com tendências à obtenção das "melhores" avaliações. As principais tendências identificadas sugerem que, apesar de os contatos com os funcionários serem potencialmente

\section{Gráfico 2 - Distâncias versus disparidades para a dimensionalidade escolhida}

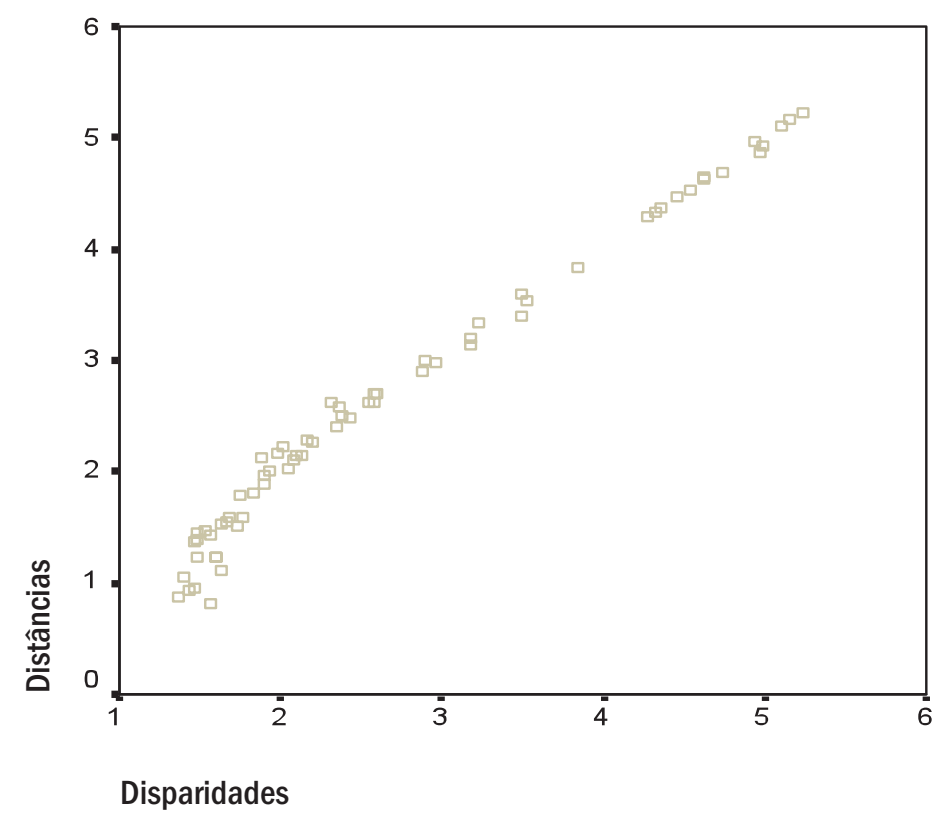


mais intensos, os "relacionamentos laterais" terem importância maior quando comparado às relações anteriores e os históricos de interações continuarem a ser valorizados, as partes envolvidas nessas díades em geral são encaradas como interagindo com foco no médio prazo. Embora os parceiros tendam a ser percebidos como comprometidos com a relação, eles são vistos como não encontrando grandes dificuldades para romper os vínculos. Como os objetivos e desejos de cada uma das partes tendem a ser percebidos como compatíveis e os relacionamentos como produtivos, acredita-se que elas sejam mais transparentes uma com a outra, possuam, talvez justamente por isso, um nível mais elevado de segurança e confiança mútua, ajam levando em consideração os interesses dos outros e façam concessões recíprocas com maior frequência. Possivelmente em decorrência de tais aspectos, os elementos dessas relações tendem a ser percebidos como agentes que procuram conciliar esforços em prol do benefício mútuo, sem procurar levar vantagem uns sobre os outros. Embora a um dos parceiros tenda a ser atribuída um pouco mais de capacidade para influenciar as ações do outro, o desequilíbrio de poder nesses relacionamentos é encarado com magnitude reduzida. Verifica-se ainda que essas relações tendem a ser percebidas como estimulantes, concretizadas por interações emocionais, amigáveis e harmoniosas, permeadas por respeito e que fazem com

Tabela 3 - Médias das avaliações dos atributos pesquisados em cada linha de serviço

\begin{tabular}{|c|c|c|c|c|c|c|c|c|c|c|c|c|}
\hline ATRIBUTO/ESTÍMULO & ACA & AGE & BAN & CAR & ESC & FAR & LOC & RES & SUP & SAL & TRA & TEL \\
\hline AT1 & 3,58 & 4,35 & 5,15 & 5,19 & 3,28 & 3,80 & 3,39 & 3,79 & 4,28 & 3,51 & 4,23 & 4,87 \\
\hline AT2 & 3,11 & 3,80 & 4,44 & 4,37 & 2,86 & 3,37 & 3,09 & 3,24 & 3,68 & 3,12 & 4,06 & 4,14 \\
\hline AT3 & 2,53 & 3,11 & 3,89 & 3,92 & 2,68 & 2,93 & 2,72 & 2,96 & 3,30 & 2,62 & 3,95 & 3,95 \\
\hline AT4 & 3,19 & 3,75 & 4,59 & 4,66 & 3,08 & 3,43 & 3,15 & 3,27 & 3,88 & 3,08 & 4,25 & 4,45 \\
\hline AT5 & 3,28 & 4,32 & 4,96 & 4,83 & 3,48 & 3,78 & 3,62 & 3,77 & 4,30 & 3,58 & 4,58 & 4,62 \\
\hline AT6 & 3,18 & 3,73 & 4,35 & 4,36 & 3,07 & 3,55 & 3,07 & 3,47 & 3,91 & 3,18 & 4,25 & 4,39 \\
\hline AT7 & 2,67 & 3,20 & 4,08 & 4,10 & 2,76 & 3,19 & 2,63 & 3,04 & 3,50 & 2,72 & 3,78 & 4,14 \\
\hline AT8 & 2,85 & 3,24 & 4,36 & 4,27 & 2,96 & 3,64 & 2,96 & 3,17 & 3,88 & 3,12 & 3,83 & 4,25 \\
\hline AT9 & 3,52 & 4,00 & 5,08 & 5,01 & 3,58 & 4,31 & 3,60 & 3,99 & 4,63 & 3,46 & 4,94 & 4,92 \\
\hline AT10 & 2,67 & 3,66 & 3,77 & 3,88 & 2,65 & 3,51 & 3,30 & 3,41 & 3,52 & 3,09 & 4,28 & 4,06 \\
\hline AT11 & 2,86 & 3,69 & 4,21 & 4,41 & 3,12 & 3,88 & 3,64 & 3,83 & 3,84 & 3,36 & 4,78 & 4,27 \\
\hline AT12 & 3,08 & 3,60 & 4,07 & 4,13 & 3,44 & 3,82 & 3,44 & 3,67 & 4,09 & 3,53 & 4,46 & 4,16 \\
\hline AT13 & 2,89 & 3,85 & 4,45 & 4,72 & 2,64 & 3,64 & 3,16 & 3,60 & 3,95 & 3,00 & 4,88 & 4,64 \\
\hline AT14 & 2,70 & 3,41 & 3,69 & 3,86 & 2,69 & 3,15 & 2,97 & 3,12 & 3,48 & 2,80 & 3,75 & 3,84 \\
\hline AT15 & 2,89 & 3,27 & 4,43 & 4,31 & 3,06 & 2,79 & 2,57 & 2,70 & 3,09 & 2,97 & 3,25 & 3,95 \\
\hline AT16 & 3,55 & 3,61 & 4,71 & 4,72 & 4,01 & 3,11 & 3,20 & 3,14 & 3,67 & 3,58 & 3,67 & 4,42 \\
\hline AT17 & 3,04 & 3,67 & 4,33 & 4,46 & 3,11 & 3,53 & 3,17 & 3,48 & 3,82 & 3,08 & 4,02 & 4,51 \\
\hline AT18 & 2,93 & 3,72 & 3,93 & 4,02 & 2,76 & 3,18 & 2,83 & 3,26 & 3,55 & 3,20 & 3,78 & 4,02 \\
\hline AT19 & 3,17 & 3,60 & 3,65 & 3,67 & 3,01 & 3,60 & 3,49 & 3,77 & 3,92 & 3,05 & 4,08 & 3,93 \\
\hline AT20 & 2,98 & 3,42 & 4,37 & 4,33 & 3,08 & 3,72 & 3,41 & 3,67 & 4,03 & 3,11 & 3,92 & 4,40 \\
\hline AT21 & 3,07 & 3,95 & 4,44 & 4,42 & 3,12 & 3,67 & 3,42 & 3,77 & 4,22 & 3,19 & 4,05 & 4,55 \\
\hline AT22 & 2,61 & 3,27 & 3,58 & 3,57 & 2,62 & 3,13 & 2,79 & 2,91 & 3,34 & 2,65 & 3,52 & 3,91 \\
\hline AT23 & 3,91 & 3,81 & 2,92 & 3,06 & 3,61 & 3,76 & 3,87 & 3,76 & 3,49 & 4,22 & 3,00 & 3,36 \\
\hline AT24 & 3,20 & 3,34 & 3,35 & 3,42 & 2,64 & 3,76 & 3,23 & 3,58 & 3,75 & 2,83 & 3,47 & 3,63 \\
\hline
\end{tabular}

Legenda: ACA: Academia de ginástica; AGE: Agência de viagens; BAN: Banco; CAR: Cartão de crédito; ESC: Escola de idiomas; FAR: Farmácia; LOC: Locação de Filmes; RES: Restaurante fast-food; SUP: Supermercado; SAL: Salão de beleza; TRA: Transporte aéreo; TEL: Telefonia móvel. 
que os interagentes se sintam próximos uns dos outros.

Analisando-se agora as relações que, de um modo geral, obtêm avaliações "intermediárias", verifica-se a formação de um grupo composto pelos relacionamentos estabelecidos entre consumidores e empresas que atuam respectivamente no segmento de supermercado, restaurante fast-food, farmácia e agência de viagens. Assim como nas quatro últimas linhas de serviço analisadas, observa-se que a oferta desses serviços tanto pode ser realizada por grandes empresas (sejam elas franquias ou múltiplos estabelecimentos de uma rede) como (aparentemente com maior frequência) por organizações menores e de atuação restrita à esfera local. Destaca-se que os consumidores desses serviços tanto podem interagir com as empresas se utilizando principalmente da tecnologia (pela internet ou por telefone), como no caso das quatro primeiras linhas de serviço, quanto podem interagir pessoalmente com funcionários dessas organizações. Neste último caso, verifica-se que os "relacionamentos laterais" não assumem grande relevância no pacote total de benefícios obtidos (ou buscados) pelos consumidores. Além disso, percebe-se que na oferta dos serviços em questão ocorre transferência de elementos tangíveis, e os componentes variedade, preço baixo e conveniência são bastante valo- rizados por muitos consumidores, os quais podem, com isso, construir múltiplos relacionamentos com empresas concorrentes ou não construir relacionamento algum, preferindo sempre a oferta superior do momento.

No que diz respeito ao "perfil relacional" percebido para estas quatro últimas linhas de serviço, as principais tendências identificadas sugerem que, em geral, os membros das díades são encarados como interagindo com frequência moderada e mais ou menos intensa, com foco no curto prazo, com níveis moderados de comprometimento com a relação, sem valorizarem muito o histórico de interações e sem grandes dificuldades para romper os vínculos que estabeleceram entre si. Verifica-se ainda que essas relações tendem a ser percebidas como concretizadas por interações informais, amigáveis e harmoniosas, permeadas por respeito, mas que ainda assim fazem com que os interagentes se sintam um pouco distantes uns dos outros.

Com base nas características que acabaram de ser descritas, após o escalonamento multidimensional, os relacionamentos entre consumidores e empresas de serviços foram agrupados conforme pode ser observado no Gráfico 3.

A dimensão 1 pode ser interpretada como "dominação da relação". Os relacionamentos localizados mais à esquerda do ponto de origem desse eixo podem ser con-

\section{Gráfico 3 - Mapa perceptual dos relacionamentos entre consumidores e empresas de serviço}

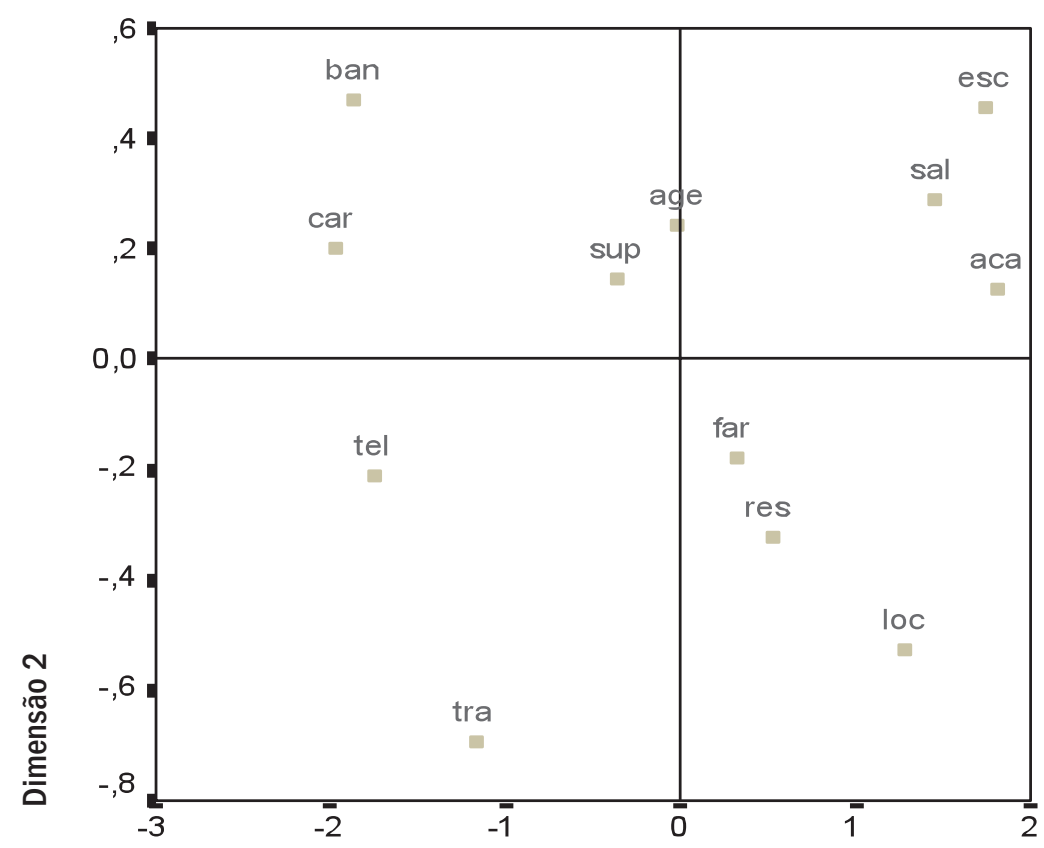

Dimensão 1 
siderados dominados pela empresa, ou seja, ela (normalmente uma grande instituição, obrigada a lidar com uma grande quantidade de clientes) é quem "dita as regras" da relação, determina como os consumidores devem ser comportar e qual tratamento eles receberão. Nesses relacionamentos, as empresas arrumam meios de diferenciar (publicamente) os seus clientes prediletos e a eles oferecem um tratamento especial, o qual pode ser considerado discriminatório pelos consumidores que por alguma razão se sentem excluídos. Aparentemente, nesses relacionamentos, a empresa atribui muito mais valor aos vínculos estabelecidos com o consumidor do que aquele geralmente atribuído por este último. Pode-se supor, inclusive, que os consumidores mantenham vínculos com as empresas desses tipos de serviços impelidos principalmente pelas forças das circunstâncias do estilo de vida que levam. Os relacionamentos localizados mais à direita nessa dimensão podem ser considerados dominados pelo consumidor. Nesses relacionamentos, os consumidores assumem papéis mais ativos no consumo do serviço e na condução da relação. Ao contrário do que pode ser verificado nos relacionamentos anteriores, o histórico de interações do consumidor com empresas provedoras desses tipos de serviços não é algo que seja normalmente utilizado como base para a criação de categorias ou faixas de clientes preferenciais. Pode-se supor também que os consumidores, por encontrarem mais liberdade nas interações, sintam-se mais satisfeitos com a qualidade dos laços que forjaram e que os "relacionamentos laterais" tenham a mesma (ou até maior) importância atribuída por eles aos relacionamentos estabelecidos com as empresas.

A dimensão 2 pode ser interpretada como "intensidade da relação". Os relacionamentos localizados mais acima do ponto de origem deste eixo podem ser considerados como de alta intensidade. Nestes relacionamentos, os parceiros geralmente interagem com grande freqüência, focam prioritariamente o longo prazo nas interações e encontram dificuldades para romper os vínculos que estabeleceram entre si. Os relacionamentos localizados mais abaixo podem ser considerados como de baixa intensidade. Em tais relacionamentos, os parceiros geralmente interagem com baixa freqüência, focam prioritariamente o curto prazo nas interações e encontram poucas dificuldades para romper os vínculos que estabeleceram entre si.

\section{CONSIDERAÇÕES FINAIS}

Programas de relacionamento com clientes vêm sendo cada vez mais desenvolvidos pelas empresas de serviço.
A concepção de tais programas quase sempre é realizada de forma monológica, isto é, as empresas são quem decide com quem querem se relacionar e qual formato o relacionamento deve assumir. Contudo, um relacionamento é algo intrinsecamente dialógico, e, como os consumidores não são todos iguais, cada um deles pode desejar uma forma diferente de relacionamento com uma mesma empresa. A questão passa a ser então identificar qual o formato de relacionamento cada consumidor deseja. Diante disso, as empresas de serviço podem procurar agrupar os seus consumidores com base não mais apenas em suas características, mas na forma como eles percebem e/ou desejam o relacionamento. Para realizarem isso, elas devem monitorar a percepção que os consumidores possuem acerca do relacionamento e, a partir daí, moldar a natureza de suas interações com eles. As características que puderam ser identificadas como diferenciadoras dos relacionamentos no contexto de consumo de serviços foram "dominação" e "intensidade", as quais estão em relativa consonância com os resultados de Wish (1976); Wish, Deutsch e Kaplan (1976) e Iacobucci e Ostrom (1996).

O presente estudo demonstrou empiricamente que até mesmo os relacionamentos dos consumidores com empresas prestadoras de serviços diferentes podem assumir, na visão deles, características similares. Mas se essas características não puderem ser consideradas efetivas, quais benchmarkings, por assim dizer, poderão ser utilizados? A resposta requer o conhecimento da forma como os consumidores concebem os vários relacionamentos com as empresas de serviços e a identificação das características dos serviços que estão mais associadas aos melhores relacionamentos.

Em face aos resultados encontrados neste estudo, pode-se argumentar que as propriedades de cada serviço influenciam de forma diferente a natureza do relacionamento da empresa com seu consumidor. Mesmo que isso se mostre irrefutável para todos os contextos, tais propriedades provavelmente não serão os únicos fatores atuantes e, possivelmente, estruturas semelhantes poderão ser encontradas nos relacionamentos dos consumidores com empresas de serviços de natureza totalmente díspares, já que aquilo que está sob análise são as relações e não os serviços. Do mesmo modo, o agrupamento de consumidores com base em algumas características semelhantes pode não ser suficiente para justificar as diferenças e similaridades encontradas na forma como eles se relacionam com empresas de diferentes tipos de serviço.

Como fundamento para essa perspectiva, observa-se que os trabalhos antropológicos de Lévi-Strauss (1996, 2003) já demonstraram que diferentes relacionamentos 
podem compartilhar de uma mesma estrutura, ainda que os parceiros envolvidos tenham características distintas em cada caso. Assim, o relacionamento que ocorre entre um dado indivíduo que substancia o termo "tio materno" e outro que substancia o termo "sobrinho" pode possuir determinadas semelhanças com certo relacionamento entre pai e filho, por exemplo, ainda que nenhum deles tenha plena consciência disso. Será então que fenômeno similar ocorre nos relacionamentos entre os consumidores e empresas de diversos tipos de serviços?

Noutros termos, ainda que os parceiros envolvidos em cada relação variem e que cada relacionamento seja único (cf. DWYER, 2000), será que, quando analisados em conjunto sob uma perspectiva sincrônica (ver LÉVISTRAUSS, 1996; WALLE, 1998; LEVY, 1981, 1999) e dialógica (considerando-se a percepção dos dois lados da díade), a inter-relação entre esses relacionamentos fará emergir as suas estruturas? Será que consumidores com algumas características diferentes (gênero, idade, etc.) poderão manter e intencionar relacionamentos com empresas de diferentes serviços que compartilhem alguma(s) estrutura(s)? Mais especificamente, será que um consumidor pode estabelecer e intencionar um relacionamento com uma empresa de um determinado tipo de serviço com algumas estruturas similares ao relacionamento mantido por ele próprio ou por outro consumidor com uma empresa de outro tipo de serviço?

Essas são questões interessantes que podem ser aprofundadas por pesquisas qualitativas que explorem simultaneamente as características e percepções dos dois lados da díade nos mais variados contextos de serviços e de consumidores.

\section{REFERÊNCIAS}

ANDERSON, W. Deciphering dyads: concepts, methods, and controversies in relational research. Psychology \& Marketing, v. 11, n. 5, p. 447-466, 1994.

BAGOZZI, R. Reflections on relationship marketing in consumer markets. Journal of the Academy of Marketing Science, v. 23, n. 4, p. 272-277, 1995.

BARNES, J. Closeness, strength, and satisfaction: examining the nature of relationships between providers of financial services and their retail customers. Psychology \& Marketing, v. 14, n. 8, p. 765-90, 1997.

BARNES, J. Segredos da gestão pelo relacionamento com os clientes. Rio de Janeiro: Qualitymark, 2002.

BAUMAN, Z. Postmodernism and its discontents. London: Polity, 1998.

BAZILLI, C e outros. Interacionismo simbólico e teoria de papéis. São Paulo: Educ, 1998.
BERRY, L. Relationship marketing of services: growing interest, emerging perspectives. Journal of the Academy of Marketing Science, v. 23, n. 4, p. 236-245, 1995.

BERRY, L. Relationship marketing of services: perspectives from 1983 and 2000. Journal of Relationship Marketing, v. 1, n. 1, p. 59-77, 2002.

BITNER, M. Building service relationships: it's all about promises. Journal of the Academy of Marketing Science, v. 23, n. 4, p. 246-51, 1995.

BLUMER, H. Symbolic Interactionism. Berkeley: University of California Press, 1969.

BORG, I; GROENEN, P. Modern Multidimensional Scaling. New York: Springer, 1997

CARROLL, J; GREEN, P. Psychometric methods in marketing research: part II, multidimensional scaling. Journal of Marketing Research, v. 34, n. 2, p. 193-204, 1997

COLLIOT-THÉLÈNE, C. Max Weber e a história. São Paulo: Brasiliense, 1995.

CZEPIEL, J. Service encounters and service relationships: implications for research. Journal of Business Research, v. 20, n. 1, p. 13-21, 1990.

DAY, G. Managing market relationships. Journal of the Academy of Marketing Science, v. 28, n. 1, p. 24-30, 2000.

DWYER, D. Interpersonal Relationships. London: Routledge, 2000.

FOURNIER, S. Consumer and their brands: developing relationship theory in consumer research. Journal of Consumer Research, v. 24, n. 4, p. 343-373, 1998.

FOURNIER, S. A Consumer-Brand Relationship Framework for Strategic Brand Management, Ph.D. Dissertation, University of Florida, USA, 1994.

FOURNIER, S; DOBSCHA, S; MICK, D. Preventing the premature death of relationship marketing. Harvard Business Review, v. 76, p. 42-51, 1998.

GOSLING, M; GONÇALVES, C. Estratégias de relacionamentos em bancos: um estudo empírico. In: ENCONTRO NACIONAL DA ASSOCIAÇÃO NACIONAL DOS PROGRAMAS DE PÓS-GRADUAÇÃO EM ADMINISTRAÇ̃̃O, 26, 2002, Salvador. Anais. Salvador: ANPAD, 2002.

GRAYSON, K; AMBLER, T. The dark side of long-term relationships in marketing services. Journal of Marketing Research, v. 36, n. 1, p. 132141, 1999.

GREEN, P; RAO, V. Applied Multidimensional Scaling: a Comparison of Approaches and Algorithms. Hinsdale: Dryden, 1972.

GRÖNROOS, C. Service Management and Marketing: A Customer Relationship Approach. 2. ed. Chichester: John Wiley \& Sons, 2000.

HAIR, J. e outros. W. Análise multivariada de dados. 5. ed. Porto Alegre: Bookman, 2005 
HAYS, R. Friendship. In: DUCK, S. (Ed) Handbook of Personal Relationships. New York: John Willey, 1988. p. 391-408.

HEIDER, F. The Psychology of Interpersonal Relations. Hillsdale: Lawrence Erlbaum, 1958.

HINDE, R. Towards Understanding Relationships. London: Academic Press, 1979.

HOLMLUND, M. Perceived Quality in Business Relationships. Helsink: Swedish School of Economics and Business Administration Library, 2000.

IACOBUCCI, D; OSTROM, A. Commercial and interpersonal relationships: using the structure of interpersonal relationships to understand individual-to-individual, individual-to-firm, and firm-to-firm relationships in commerce. International Journal of Research in Marketing, v. 13, n. 1, p. 53-72, 1996.

KALE, S; SHRIVASTAVA, S. Relationship marketing theory for consumer markets: suggestions for an alternative ontological and epistemological perspective. Working Paper, 20 p, 2001.

LEHTINEN, U. Our present state of ignorance in relationship marketing. Asia-Australia Marketing Journal, v. 4, n. 1, p. 43-51, 1996.

LÉVI-STRAUSS, C. Antropologia estrutural. 5. ed. Rio de Janeiro: Tempo Brasileiro, 1996.

LÉVI-STRAUSS, C. As estruturas elementares do parentesco. 3. ed. Petrópolis: Vozes, 2003.

LEVY, S. Interpreting consumer mythology: a structural approach to consumer behavior. Journal of Marketing, v. 45, n.3, p. 49-61, 1981

LEVY, S. Synchrony and diachrony in product perceptions. In: LEVY, S. Brands, Consumers, Symbols, and Research. Sage: London, 1999. p. 390-405.

LOVELOCK, C. Classifying services to gain strategic marketing insights. Journal of Marketing, v. 47, n. 3, p. 9-20, 1983.

MEAD, G. H. Mind, self and society. Chicago: University of Chicago, 1934.

MELLO, S; LEÃO, A; SOUZA NETO, A. O "papel" dos encontros de serviço na formação e na manutenção de relacionamentos. Gestão.org, v. 2, n. 1, p. 50-64, 2004.

NETER, J; WASSERMAN, W; KUTNER, M. Applied Linear Statistical Models: Regression, Analysis, and Variance Designs. 3. ed. Boston: Irwin, 1990.

O'MALLEY, L; PATTERSON, M; EVANS, M. Intimacy or intrusion: the privacy dilemma for relationship marketing in consumer markets. Journal of Marketing Management, v.13, n. 6, p. 541-60, 1997.

O'MALLEY, L; TYNAN, C. Relationship marketing in consumer markets: rhetoric or reality? European Journal of Marketing, v. 34, n. 7, p. 797815,2000 .

PERIN, M. e outros. As relações entre confiança, valor e lealdade: um estudo intersetorial. ENCONTRO NACIONAL DA ASSOCIAÇÃO NACIONAL DOS PROGRAMAS DE PÓS-GRADUAÇÃO EM ADMINISTRAÇÃO, 28, 2004, Curitiba. Anais. Curitiba: ANPAD, 2004.
ROSENBERGER, G. Relationship marketing from a consumer policy perspective. In: HENNIG-THURAU, T; HANSEN, U. (Eds) Relationship marketing: gaining competitive advantage through customer satisfaction and customer retention. Berlin: Springer-Verlag, 2000, p.353-67.

SAREN, M; TZOKAS, N. Some dangereous axioms of relationship marketing. Journal of Strategic Marketing, v. 6, n. 3, p.187-196, 1998

SHEAVES, D; BARNES, J. The fundamentals of relationships: an exploration of the concept to guide marketing implementation. In: SWARTZ, T; BROWN, S. (Ed) Advances in Services Marketing and Management. v. 5. Greenwich: JAI Press, 1996. p. 215-245.

SHETH, J; PARVATIYAR, A. Evolving relationship marketing into a discipline. Journal of Relationship Marketing, v. 1, n. 1, p. 3-16, 2002.

SHETH, J; PARVATIYAR, A. Relationship marketing in consumer markets: antecedents and consequences. Journal of Academy of Marketing Science, v. 23, n. 4 , p. $255-271,1995$.

SOUZA, R; BUSSAB, W. Participação de mercado: uma abordagem multidimensional escalar. ENCONTRO NACIONAL DA ASSOCIAÇÃO NACIONAL DOS PROGRAMAS DE PÓS-GRADUAÇÃO EM ADMINISTRAÇÃO, 27, 2003, Atibaia. Anais. Atibaia: Anpad, 2003.

SOUZA NETO, A. e outros. Voltando o carro para trás dos bois: busca pela compreensão de nuances do "relacionamento" no contexto de consumo como forma de subsidiar a prática consciente do "marketing de relacionamento" por empresas de serviço. In: ENCONTRO DE MARKETING DA ASSOCIAÇÃO NACIONAL DOS PROGRAMAS DE PÓS-GRADUAÇÃO EM ADMINISTRAÇÃO, 1, 2004, Porto Alegre. Anais. Porto Alegre: ANPAD, 2004.

STALANS, L. Multidimensional scaling. In: GRIMM, L; YARNOLD, P. (Ed) Reading and Understanding Multivariate Statistics. Washington: APA, 2002. p. 137-168.

STRYKER, S; STATHAM, A. Symbolic interaction and role theory. In: LINDZEY, G; ARONSON, E. (Ed) Handbook of Social Psychology. 3. ed. New York: Random House, 1985. p. 311-378.

WALLE, A. Evolving structures and consumer response: dynamic transformations of "The Fugitive" and "Mission: Impossible". Management Decision, v. 36, n. 6, p. 399-406, 1998.

WISH, M. Comparisions among multidimensional structures of interpersonal relations. Multivariate Behavioral Research, v. 11, n. 3, p. 297-324, 1976

WISH, M; DEUTSCH, M; KAPLAN, S. Perceived dimensions of interpersonal relations. Journal of Personality and Social Psychology, v. 33, p. 409-420, 1976.

WONG, A; SOHAL, A. An examination of the relationship between trust, commitment, and relationship quality. International Journal of Retail $\&$ Distribution Management, v. 30, n. 1, p. 34-50, 2002. 